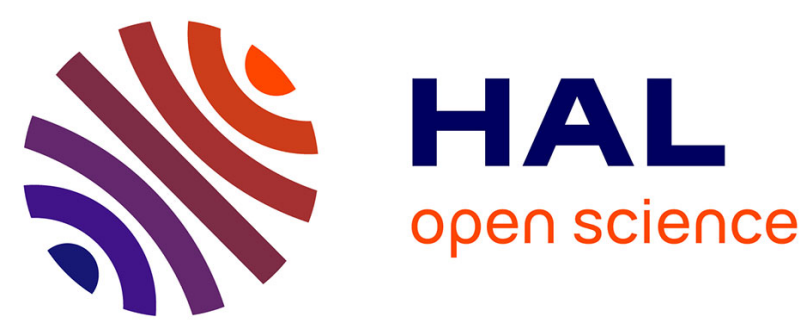

\title{
Coagulation of combustion generated nanoparticles and their measurement behind vehicle engines: can they play a role as atmospheric pollutants?
}

\author{
H.-H. Grotheer, T. Gonzalez Baquet, M. Thierley, H. Pokorny, M. Aigner
}

\section{To cite this version:}

H.-H. Grotheer, T. Gonzalez Baquet, M. Thierley, H. Pokorny, M. Aigner. Coagulation of combustion generated nanoparticles and their measurement behind vehicle engines: can they play a role as atmospheric pollutants?. Atmospheric Chemistry and Physics Discussions, 2005, 5 (3), pp.3847-3872. hal-00301578

\section{HAL Id: hal-00301578 \\ https://hal.science/hal-00301578}

Submitted on 10 Jun 2005

HAL is a multi-disciplinary open access archive for the deposit and dissemination of scientific research documents, whether they are published or not. The documents may come from teaching and research institutions in France or abroad, or from public or private research centers.
L'archive ouverte pluridisciplinaire HAL, est destinée au dépôt et à la diffusion de documents scientifiques de niveau recherche, publiés ou non, émanant des établissements d'enseignement et de recherche français ou étrangers, des laboratoires publics ou privés. 
Coagulation of nanoparticles

H.-H. Grotheer et al.

\section{Coagulation of combustion generated nanoparticles and their measurement behind vehicle engines: can they play a role as atmospheric pollutants?}

H.-H. Grotheer, T. Gonzalez Baquet, M. Thierley, H. Pokorny, and M. Aigner

DLR Institute of Combustion Technology, Pfaffenwaldring 38-40, 70569 Stuttgart, Germany

Received: 25 February 2005 - Accepted: 31 March 2005 - Published: 10 June 2005

Correspondence to: H.-H. Grotheer (hh.grotheer@dlr.de)

(c) 2005 Author(s). This work is licensed under a Creative Commons License.

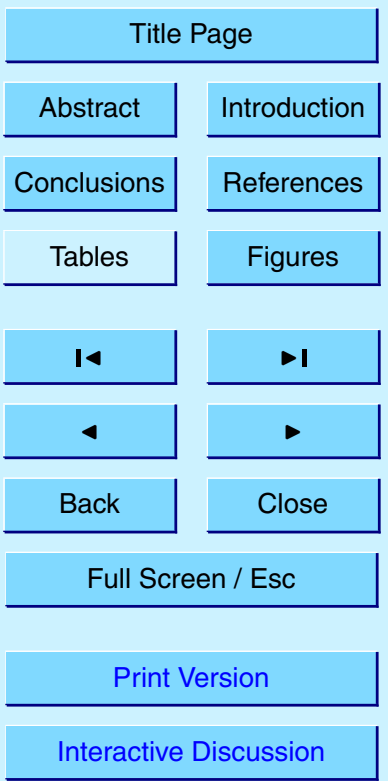

EGU 


\section{Abstract}

Based on photoionisation mass spectrometry two types of experiments were carried out. (i) In a fast flow reactor coupled to a low pressure flame as a particle source, rate coefficients for the coagulation of primary nanoparticles were measured through

5 variation of the reactor residence time. The results are $k_{c}(350 \mathrm{~K})=3.5 \cdot 10^{-10} \mathrm{~cm}^{3} / \mathrm{s}$ and $k_{c}(573 \mathrm{~K})=1.1 \cdot 10^{-9} \mathrm{~cm}^{3} / \mathrm{s}$, i.e. very high rate coefficients. It was also shown that coagulated nanoparticles can have masses beyond $50 \mathrm{ku}$, corresponding to equivalent diameters between 4 to $5 \mathrm{~nm}$. These particles are easily fragmented during photoionisation. (ii) Using a second and mobile photoionisation mass spectrometer equipped 10 with a fast flow inlet system, measurements were carried out behind three different vehicle engines, a two-stroke scooter engine, a four-stroke motorbike engine and a DI (direct injection) gasoline research engine. In all cases ion signals around $1000 \mathrm{u}$ were found that are clearly dependent on engine conditions. In the case of the DI engine, they correlate with the smoke number. These signals cannot be explained by PAHs due

to their low volatility at the respective masses. Major contributions of soot or droplet fragmentation were ruled out through additional experiments using a heated inlet line and a filter. Consequently, these signals are interpreted as fragments of coagulated nanoparticles.

\section{Introduction}

20 The unveiling of combustion generated nanoparticles as an own species group separate from soot is an ongoing story and, consequently, their potential roles as health hazard or as atmospheric pollutants are under debate. As early as 1973 Wersborg et al. (1973) discovered extremely small nanoparticles (diameters down to $1.5 \mathrm{~nm}$ ) as ions in low pressure $\mathrm{C}_{2} \mathrm{H}_{2} / \mathrm{O}_{2}$ flames. They used a molecular beam apparatus and
ACPD

5, 3847-3872, 2005

Coagulation of nanoparticles

H.-H. Grotheer et al.

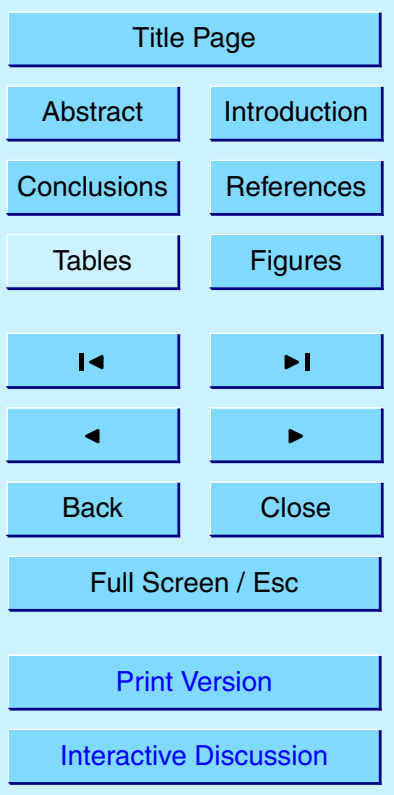

EGU differences between these small particles and mature soot. Using electron microscopy 
of beam deposits they found that the small particles display a much smaller electron density relative to soot so that they were not immediately detectable to TEM. Further differences to soot that were found by other research groups are just listed for the sake of brevity. They include

- H fraction above 0.3 (Homann and Wagner, 1967; Schulz, 1987; Dobbins et al., 1995), i.e. high in comparison to soot for which $\mathrm{H}$ fractions around 0.1 are normally found

- sizes in the low $\mathrm{nm}$ range down to less than $2 \mathrm{~nm}$ (Smyth and Mallard, 1981; Wersborg et al., 1973)

- PAH-like rather than carbonaceous structures as detected by laser microprobe mass spectrometry (Dobbins et al., 1995) together with liquid-like features found under transmission electron microscopy observation (Vander Wal, 1998; Dobbins, 1998)

- very high concentrations beyond $10^{13} \mathrm{~cm}^{-3}$ as deduced from light scattering (Minutolo et al., 1999)

- optical properties indicating a composition consisting of 2- or 3-ring substructures that are tied together through aliphatic C-C-bonds or oxygen bridges (D'Alessio et al., 1992, 1998)

The latter feature leads to the consequence that nanoparticles are transparent in the visible and this may be the reason why they have so far escaped a widespread attention, although they are suspected to be emitted from internal combustion engines in rather high numbers. Exemplary number densities are reported as high as $10^{12} \mathrm{~cm}^{-3}$ behind a gasoline engine and even $5 \cdot 10^{12} \mathrm{~cm}^{-3}$ behind a Diesel engine (Sgro et al., 2003). Although these emissions are relatively small on a mass basis, their number 25 densities exceed those of soot by orders of magnitude as a result of the small sizes involved. This then may lead to health effects which may be even enhanced through
ACPD

5, 3847-3872, 2005

Coagulation of nanoparticles

H.-H. Grotheer et al.

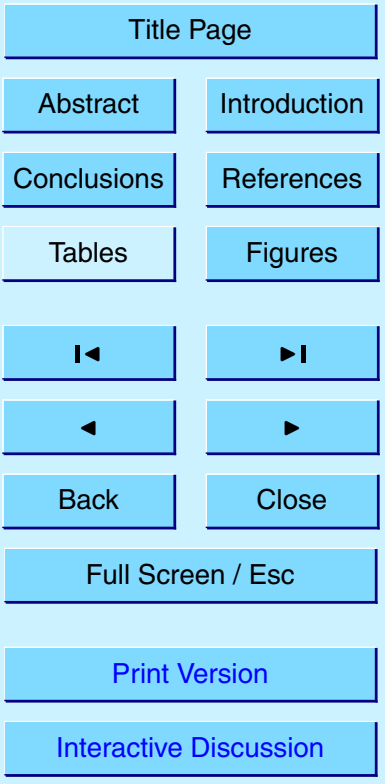

EGU 
the water-solubility of these particles (Sgro et al., 2003). These workers have also contributed to the measurement of nanoparticles during engine combustion or behind engines. UV absorption and scattering was used directly for in situ measurements in the combustion chamber (Violi et al., 2000; Vaglieco et al., 2002) or in the exhaust gas 5 (Borghese and Merola, 1998; Merola et al., 2001). Alternatively, in the latter studies wet nanoparticle samples were drawn and analyzed using absorption and/or fluorescence. With relevance to the present study, in several papers from these research groups (Minutolo et al., 1999; Sgro et al., 2001) it is pointed out that organic carbon constitutes a major portion of the atmospheric aerosol and that many of its constituents 10 could yet not be identified. These authors conclude that the possibility cannot be rejected that nanoparticles with $\mathrm{PAH}$-like substructures emitted from vehicle exhaust may significantly contribute to the organic matter in the atmosphere. In proof of this Merola et al. (2001) measured UV absorption spectra of rain. In particular at the beginning of the precipitation, spectra were found with a high extinction in the UV decreasing towards longer wavelengths. This type of spectra is characteristic for nanoparticles as measured in situ or in wet samples drawn behind engines. Goal of the present study is a contribution to the question whether nanoparticles can be released in significant amounts into the atmosphere. To this end we pursued two approaches which are based on the use of mass spectrometry for nanoparticle detection (Grotheer et al., 20 2004).

1. It is attemped in the present paper to find out an average coagulation coefficient for nanoparticles. Such a number would be important in two regards: Within a flame it is the competition between coagulation and aromatisation which determines whether a nanoparticle grows up as such or, alternatively, is immediately transformed into soot. In addition, in a practical combustion system coagulation determines whether nanoparticles once released from the flame can survive an exhaust train so that their emission may become a health hazard.

2. Using a mobile system equipped with an atmospheric pressure sampling device

ACPD

$5,3847-3872,2005$

Coagulation of nanoparticles

H.-H. Grotheer et al.

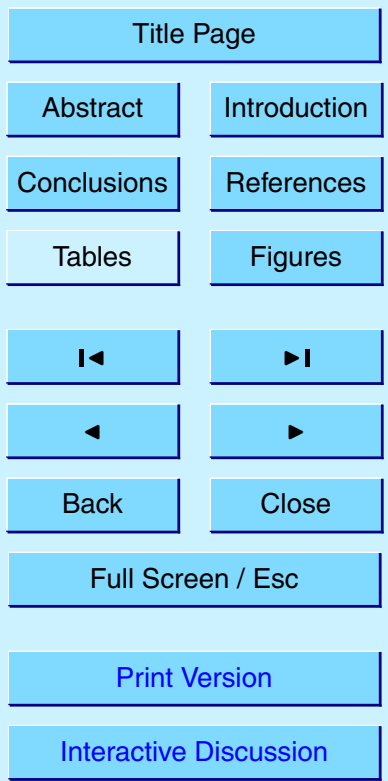

EGU 
as reported recently (Barth et al., $2005^{1}$ ) we started to perform exhaust gas tests ACPD using a motor scooter with a two-stroke engine. Next, as an example of a fourstroke engine we used a motor bike. Both tests were carried out in our laboratory and this allowed only studies under idling conditions as there is no vehicle test stand at our disposal. As a third step we transported our system to an industrial engine test stand to measure particles behind a DI gasoline research engine under controlled conditions.

The results of these approaches are partly conflicting, yet they demonstrate that nanoparticles can escape from an exhaust train and that a more detailed investigation is needed.

\section{Experimental}

15 For the kinetic measurements we generated nanoparticles and other flame species in a movable low pressure burner $\left(\mathrm{C}_{2} \mathrm{H}_{4} / \mathrm{O}_{2}, 130 \mathrm{mbar}\right)$ as shown in Fig. 1 . The burner discharged via a nozzle into a fast flow reactor which in turn was connected via a molecular beam inlet to the MS. The combination of these two stages and the individual selection of operation conditions yields a high versatility of our apparatus. Thus, through selection of the distance between burner and nozzle (height above burner, $\mathrm{HaB})$ and of the stoichiometry, the relative amounts of nanoparticles, soot and flame PAHs entering the reactor, could be controlled. Variation of the flow reactor conditions (pressure, flow of carrier gas) enabled a deduction of kinetic parameters of nanoparticle reactions. The supersonic nozzle between burner and flow reactor made it possible that conditions of the latter could be changed without influencing the flame. Therefore, within a series of reactor conditions a constant composition of the reactive gas under

\footnotetext{
${ }^{1}$ Barth, K. L., Gonzalez Baquet, T., Grotheer, H. H., and Aigner, M.: Detection of nanoparticles (soot precursors) in atmospheric diffusion flames using a mass spectrometer and a novel inlet system, Combust. Sci. Technol., submitted, 2005.
}

\section{Coagulation of nanoparticles}

H.-H. Grotheer et al.

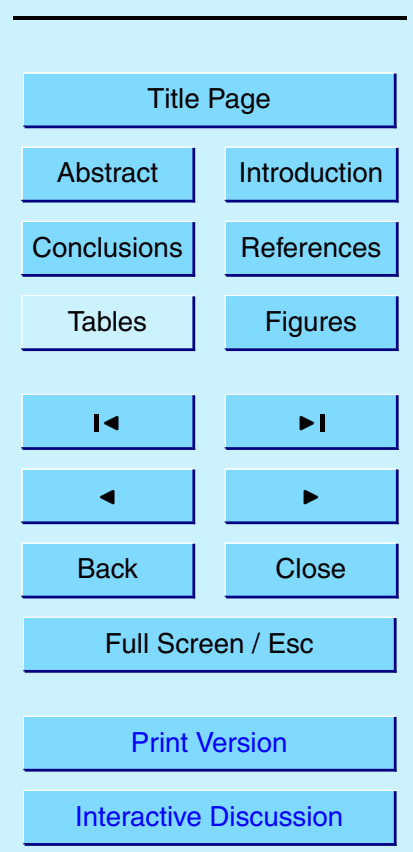

EGU 
investigation was always guaranteed. A more detailed description may be found in the literature (Grotheer et al., 2004). A commercial reflectron time-of-flight MS was modified to make detection of heavier ions possible (up to $2000000 \mathrm{u}$ ) and it was equipped with a photoionization source (ArF excimer laser, $10 \mathrm{~ns}$ pulse length). By means of at5 tenuators we could use pulse energies between 0.1 and $5 \mathrm{~mJ}$. The beam was focussed through a $150 \mathrm{~mm}$ cylindrical lens.

For the exhaust gas measurement a second reflectron mass spectrometer was equipped with a fast flow sampling system designed to suppress undesired reactions in the sampling line, see Fig. 2. Sample gas is drawn through a supersonic nozzle 10 (0.6 mm diameter) into a quartz or stainless steel tube $(10 \mathrm{~mm}$ id). Pressures in the sampling tube are between 4 and 15 mbar. Consequently, for atmospheric samples all concentrations were immediately reduced at the location of sampling by a factor of at least 60 . The concentration drop together with our short residence times of only some ms leads to a reduced influence of fast subsequent reactions. This is obviously at the expense of sensitivity as most of the sample is lost into the forepump. Another disadvantage of our sampling method is that it needs relatively large sample gas flows of about $1.5 \mathrm{slm}$. For the measurement of vehicle exhaust gas, however, the required input flow should not provide a problem. Unfortunately, this system is not capable of measuring ions beyond about $100000 \mathrm{u}$ so that soot could not be detected although it clearly entered the ion source. This contrasts to our stationary unit (same manufacturer) which allowed to measure ions as heavy as $2000000 \mathrm{u}$ (Grotheer et al., 2004). The mass scale of our mass spectrometers is known through frequent calibrations. The sensitivity of our ion signals, however, could not yet be determined. Mass spectra were usually obtained as averages over 10000 laser shots.

ACPD

5, 3847-3872, 2005

Coagulation of nanoparticles

H.-H. Grotheer et al.

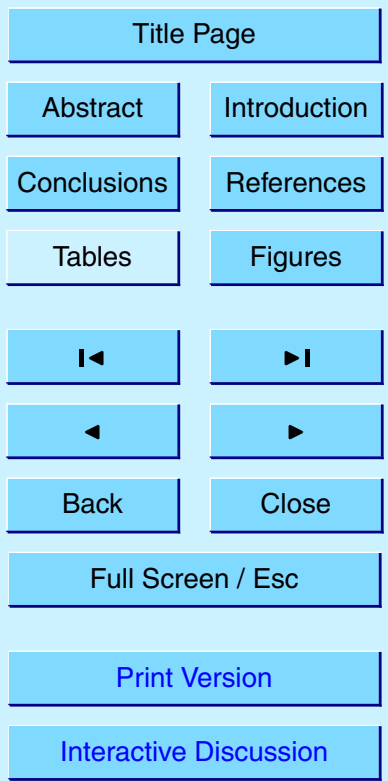

EGU 
Figure 3 is a result obtained with our laboratory setup and it is shown here as it provides some insight into the photo-ionisation of nanoparticles. Due to the loglog-display a very broad intensity range and masses ranging from common PAH molecules well into the soot region can be seen. Details of the mass spectra are lost because a large 5 bin width of the multiscaler of the mass spectrometer was used in order to gain sensitivity. In addition, a smoothing function was applied to the measured data. The mass spectra were recorded for laser pulse energies between 0.25 and $4 \mathrm{~mJ}$. For clarity only these two extremes along with the $0.5 \mathrm{~mJ}$ curve are shown. First of all one notices three distinct maxima. Around $1000 \mathrm{u}$ is the distribution of primary nanoparticles, around $400 \mathrm{ku}$ the one of primary soot particles (see also Grotheer et al., 2004), between those two is a broad distribution which we call a coagulation hump and which is thought to consist of coagulated primary particles. Interestingly, there is a wide span of more than two orders of magnitude in the ion signals of primary nanoparticles and primary soot, respectively. For laser energies between 0.25 and $0.5 \mathrm{~mJ}$ only a parallel shift of the mass spectra occurs, at least so for masses above $3 \mathrm{ku}$, indicating that there are no undesired laser effects such as fragmentation or double ionisation. If the laser energies are increased, the soot maxima are shifted towards lower masses due to fragmentation and the valley between soot and the coagulation hump is filled up with these fragments until it eventually disappears. A similar process takes place between the primary nanoparticles and the coagulation hump, albeit at somewhat lower energies. We conclude that primary soot and especially coagulated nanoparticles are very prone to fragmentation when too high laser energies are used. We could show that fullerene signals appear when this process takes place (see footnote 1 on page 3850) and we assume that fullerenes are formed from excited fragments in the ion source.

The exhaust gas measurements of this paper were mostly carried out under condi-

\section{Coagulation of} nanoparticles

H.-H. Grotheer et al.

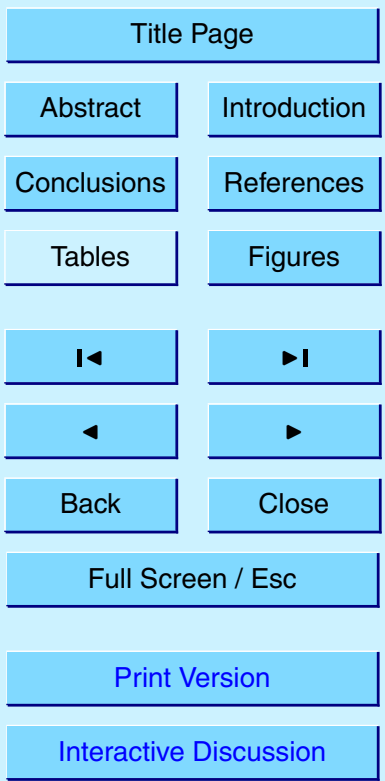

EGU 
In our previous publication (Grotheer et al., 2004) it was shown that nanoparticles form a distinct species between the more familiar PAHs (masses $<500 \mathrm{u}$ ) and soot (> several $100 \mathrm{ku}$ for primary soot) and that also their kinetic behaviour is clearly different from the one of PAHs or soot as shown by variation of flame conditions. Consequently, for the particles one expects a bimodal distribution curve consisting of a soot branch 5 and a separated nanoparticle branch. As reported above, a closer look at Figs. 3 and 4 shows that the nanoparticle distribution itself is bimodal with a relatively sharp peak between 500 and $1200 u$ that we attribute to primary nanoparticles and which is separated from a broad hump ranging from several ku to more than $50 \mathrm{ku}$. In Fig. 4 (note the log-log display) the stoichiometry, expressed as the $\mathrm{C} / \mathrm{O}$ ratio of the unburnt gases, is

10 varied. With increasing $\mathrm{C} / \mathrm{O}$ there is an increase of the primary particle concentration, yet even more primary particles are driven into coagulation to form a broad hump which not only increases in height, rather it extends to higher and higher masses. Obviously, these humps represent a second and more stable configuration of nanoparticles. It should be pointed out that the parameter varied in Fig. 4 refers to the flame conditions. What we see is consequently a mechanism taking place in the flame so that it could be partial aromatisation in addition to coagulation, whereas in the reactor aromatisation can be excluded due to the lower temperatures. For $50 \mathrm{ku}$ and assuming a density of $1.8 \mathrm{~g} / \mathrm{cm}^{-3}$ one obtaines an equivalent diameter (sphere) for coagulated nanoparticles between 4 and $5 \mathrm{~nm}$.

\subsection{Coagulation measurements}

In order to measure rate coefficients for the coagulation of primary nanoparticles, flame conditions were kept constant within a given set and the exhaust gas was allowed to react for a set of residence times. To this end the flow from the nozzle was diluted

\section{Coagulation of nanoparticles}

H.-H. Grotheer et al.

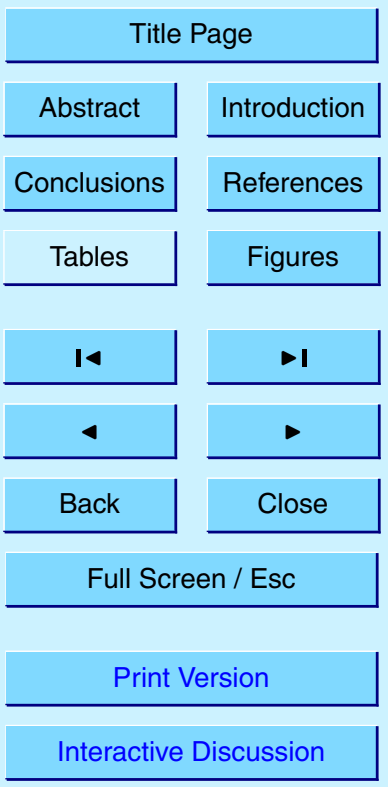

EGU 
in several steps by He carrier gas while the downstream reactor pressure was kept the reactor were decreased as well due to dilution. With regard to the nanoparticle concentrations as measured at the end of the reactor we had therefore to deal with the counterbalancing effects of reaction and dilution. This is seen in Fig. 5 (reactor temperature $350 \mathrm{~K}$ ) were the signals of primary particles remain essentially unchanged, yet for the longer times there is a clear mass increase adjacent to the primary signal, probably corresponding to a series of coagulation peaks. The coagulation humps for masses $>10$ ku remain essentially the same with a slight growth towards longer times.

5 The effect of elevated temperature $(573 \mathrm{~K})$ is shown in Fig. 6 . Here a higher $\mathrm{C} / \mathrm{O}$ ratio was used in order to counterbalance the temperature effect on the nanoparticle density so that the initial concentrations in Figs. 5 and 6 should be the same. Apparently, the primary nanoparticle signals become smaller at the longer times, i.e. the reaction has to be faster and this is even more so as at the higher temperatures the residence 10 times become shorter. Qualitatively, there is a clear coagulation peak in the high mass wing of the primary distribution. Further coagulation peaks are much less developed, perhaps so on account of a fast reaction into the coagulation hump. The latter, although small at the beginning, clearly developes towards higher masses at increased times. It would be desirable to carry out kinetic measurements of the described kind in a broad 15 range of initial nanoparticle concentrations and temperatures. On the lean side this is limited as for a ratio below $\mathrm{C} / \mathrm{O} \sim 0.83$ no clear nanoparticle signals are observed, whereas at the rich side (above $\mathrm{C} / \mathrm{O} \sim 1.1$ ) strong sooting would lead to a rapid clogging of the nozzle. The temperature range is limited as at the higher temperatures de novo formation of nanoparticles in the reactor cannot be excluded.

\section{3.4. Deduction of rate coefficients}

The formation of new nanoparticles is thought to be initiated by $\mathrm{H}$ atoms attacking aromatic compounds, requiring a considerable activation energy. Therefore, for our moderate temperatures, there is no nanoparticle formation in the flow reactor. In the
ACPD

$5,3847-3872,2005$

Coagulation of nanoparticles

H.-H. Grotheer et al.

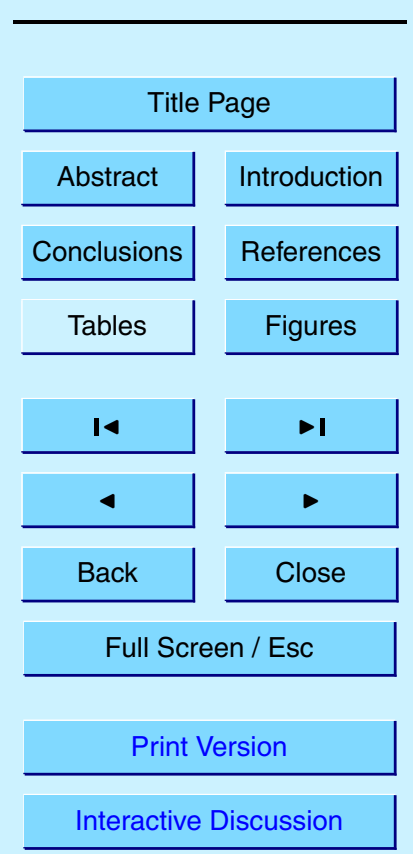

EGU 
absence of addition to soot, the nanoparticle loss is given by coagulation. In an accompanying paper (Pokorny et al., 2005) it is shown in detail how first order rate coefficients, $K$, are deduced from the profiles in Figs. 5 and 6 under consideration of flow effects such as diffusion and viscous pressure drop. Deduction of bimolecular $k_{c}$ from the first order rate coefficients $K$ requires the knowledge of the initial nanoparticle concentration in the reactor, $[N P]_{0}$ reactor. As an estimate we used $[N P]_{\text {burner }}=3 \cdot 10^{13} \mathrm{~cm}^{-3}$, 5 as reported for a rich $\mathrm{C}_{2} \mathrm{H}_{4}$ flame (Basile et al., 2002). From the ratio $p_{\text {burner }} / p_{\text {reactor }}$, this yields $[N P]_{0_{\text {reactor }}}=3 \cdot 10^{11} \mathrm{~cm}^{-3}$ leading to the results:

$$
\begin{aligned}
& -k_{c}(350 \mathrm{~K})=3.5 \cdot 10^{-10} \mathrm{~cm}^{3} / \mathrm{s} \\
& -k_{c}(573 \mathrm{~K})=1.1 \cdot 10^{-9} \mathrm{~cm}^{3} / \mathrm{s}
\end{aligned}
$$

The temperature dependence is obviously stronger than the linear T-dependence which 10 according to collisional theory has to be expected for the pre-exponential factor alone. As we use the highest concentration found in the literature, the deduced high coagulation rate coefficients are the lowest ones compatible with our measurements.

\subsection{Exhaust gas measurements: Motor-scooter (Vespa)}

The scooter, type Vespa Cosa, year of construction 1992, had a two-stroke engine with 15 a displacement of $120 \mathrm{ccm}$. It was put on a movable elevator to allow a sampling line as short as possible, i.e. $0.75 \mathrm{~m}$. The mass spectra shown in the subsequent figures refer to idling conditions under low speed. Trace (1) in Fig. 7 shows a mass spectrum obtained close to the end of the tailpipe using an unfocussed laser beam. Further upstream we get considerably more signal, trace (2), due to less dilution by ambient air 20 and due to less coagulation. This is seen when trace (1) is scaled up to match trace (2). The resulting trace (3) is augmented at the higher masses and this corresponds to coagulation which would take place in this portion of the exhaust pipe. When the laser beam was focussed by a $154 \mathrm{~mm}$ cylindrical lens, we got trace (4) instead of
ACPD

5, 3847-3872, 2005

Coagulation of nanoparticles

H.-H. Grotheer et al.

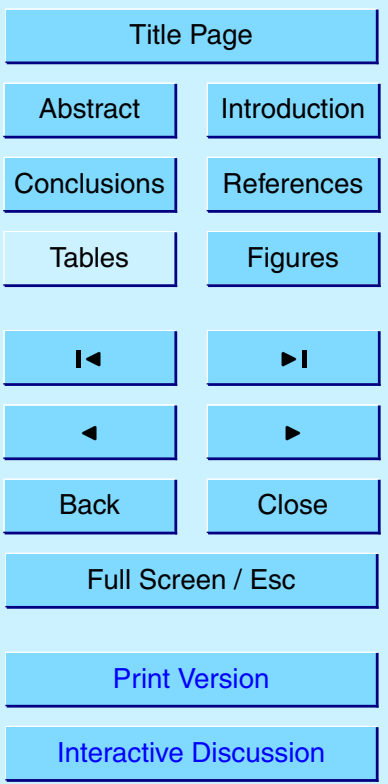

EGU 
(2) showing a fullerene-like pattern. This measurement mode was mostly used as it provides considerably larger signals.

It is interesting that these fullerene-like signals were only obtained when the sampling line was subjected to an ageing process. This is seen in Fig. 8. With a freshly cleaned line we got an elevated baseline clearly above background, yet showing no structures. 5 These start to develop after $5 \mathrm{~min}$ and reach constant values after half an hour (see inset). This is not the result of a temperature effect caused by a warm-up of the scooter since in an independent measurement, using an aged sampling line, we got fullerenelike signals immediately after starting the engine.

\subsection{Motor-bike (BMW)}

10 The motor-bike, type BMW K 100, year of manufacture 1989 , had a four-stroke engine with a displacement of $980 \mathrm{ccm}$. Again we used an elevator to keep the sampling line short. Figure 9 shows mass spectra measured about $20 \mathrm{~cm}$ upstream of the end of the exhaust pipe and as a function of the engine speed (always idling conditions). Although the ion signals are well above background, they are clearly below those of the two-stroke engine. The dependence on the engine speed is complex. Maximum signals were found at the lowest speed and lowest signals at an intermediate speed.

\subsection{DI gasoline research engine}

These measurements were carried out in the laboratories of a large industrial manufacturer. A single cylinder research engine was used, bore $85 \mathrm{~mm}$, stroke $89 \mathrm{~mm}$, mostly run at about $1000 \mathrm{rpm}$ using a gasoline-like fuel with reduced content of aromatic compounds. The engine was equipped with an optical access not needed in the present context. Samples were taken either directly after the exhaust valve or about $1.3 \mathrm{~m}$ downstream of this position. Two operation modes were tested.

1. Very early injection during the intake stroke (about $30^{\circ}$ after TDC) leads to the so-called homogeneous mode. In this case generally low emissions were found

ACPD

5, 3847-3872, 2005

Coagulation of nanoparticles

H.-H. Grotheer et al.

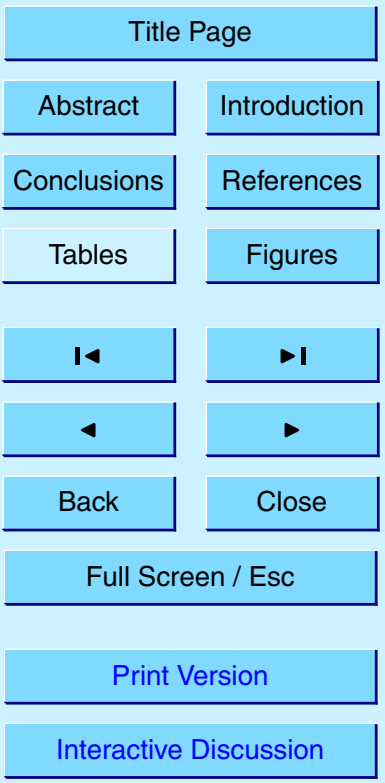

EGU 
2. Injection during compression yields the so-called stratified charge mode. The amount of injected fuel was varied through variation of the injection duration. The relative times of injection and ignition determined the mixing conditions. By these means, operating conditions could be realised leading to different amounts of produced soot. The latter was measured using an aethalometer and expressed as "smoke number". MS measurements of nanoparticles were carried out in parallel.

Some results are shown in Fig. 10. The inset of Fig. 10 demonstrates a relatively close relationship between the integrated nanoparticle spectra and the smoke number. This is actually not unexpected as both types of particles share at least a portion of the soot formation mechanism. It would be misleading, however, to assume that a nanoparticle measurement could be substituted by a measurement of the smoke number since the correlation shown in Fig. 10 can only be expected to apply for the given engine and at the given range of operation conditions. The positive intercept in the correlation line may have a physical meaning, i.e., nanoparticles exist and are mea15 surable also in the absence of soot as reported in the literature (Cecere et al., 2002). Further measurements were carried out in the exhaust train about $1.3 \mathrm{~m}$ downstream of exhaust valve. Interestingly, we got an increase of our signals which can only partly be attributed to the lower temperatures. Most notably we did not get a change in the mass spectra as should be expected when particle loss either to the wall or in the bulk takes place.

\section{Discussion}

The high rate coefficients that we found for the coagulation of primary nanoparticles look plausible as they exactly match data reported in the literature (Hinds, 1999) for particles of the given size. They are also in line with results of the working groups of Maricq (Maricq et al., 2003; Maricq, 2004) and Zhao (Zhao et al., 2003, 2004). Their

Coagulation of nanoparticles

H.-H. Grotheer et al.

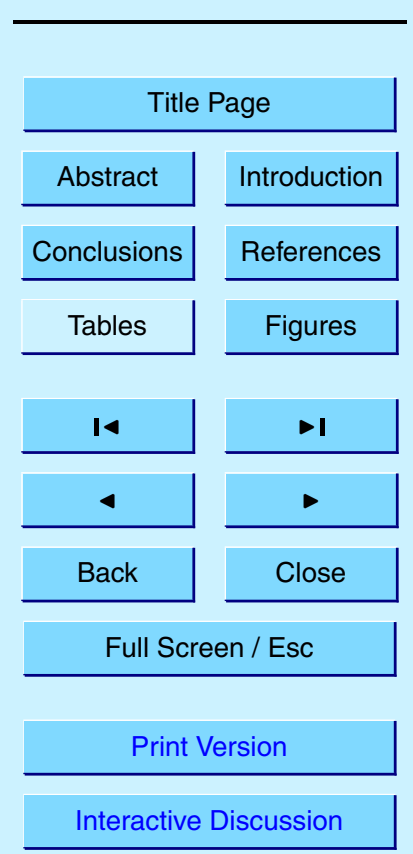

EGU 
DMA measurements of combustion generated particles showed a bimodal distribution with a clear separation of the nanoparticle signals around $2 \mathrm{~nm}$, but only so if a very high (1:10000) and immediate dilution of the sample gas was used. This means that at least some of the reactions governing nanoparticle coagulation have to be fast. On the other hand, indirect data of D'Alessio et al. (2004) and Sgro et al. (2003) deduced from nanoparticle profiles in flames yield size dependent and relatively slow rate coeffi5 cients between $1 \cdot 10^{-12}$ and $1 \cdot 10^{-9} \mathrm{~cm}^{3} / \mathrm{s}$. This may be partly caused by nanoparticle formation in the early flame. Yet it is also obvious that primary nanoparticles coagulating with our high rate coefficient would be found at the exit of an exhaust train in only very small concentrations, apparently in contradiction to our measurements. A way out of this conflict is the assumption that we actually measured heavier, i.e. coag10 ulated nanoparticles that were fragmented by the ionisation laser to yield an elevated baseline superimposed by fullerene-like signals. In favour of this view is the finding that when extending our $1.3 \mathrm{~m}$ sampling line for the DI engine measurement, by an additional piece of $1 \mathrm{~m}$, the mass spectra did not change significantly. If, however, our engine exhaust signals refer to fragments one has to ask why these fragments should stem from nanoparticles instead of, say, condensed PAHs or even soot. With regard to the latter possibility, in some experiments we equipped the sampling line with a filter (Whatman, paper no 4). In particular when the filter was fresh a major portion of our signals remained indicating that it did not originate from soot. A common approach to avoid PAH condensation is to heat the sampling line. Indeed we found that a hot sampling line $(453 \mathrm{~K})$ yielded a shift of the baseline towards larger values, yet virtually no change of the fullerene-like signals (see Gonzalez Baquet et al., 2005, for more details). We conclude that our signals measured behind vehicle engines may be associated with coagulated nanoparticles and, consequently, that these may be emitted to the atmosphere.

25 In a separate study, which will be published in 2005 , we found that these particles are very toxic to bacteria. As a result, we are dealing with a potentially very serious problem which clearly deserves further research.
ACPD

$5,3847-3872,2005$

Coagulation of nanoparticles

H.-H. Grotheer et al.

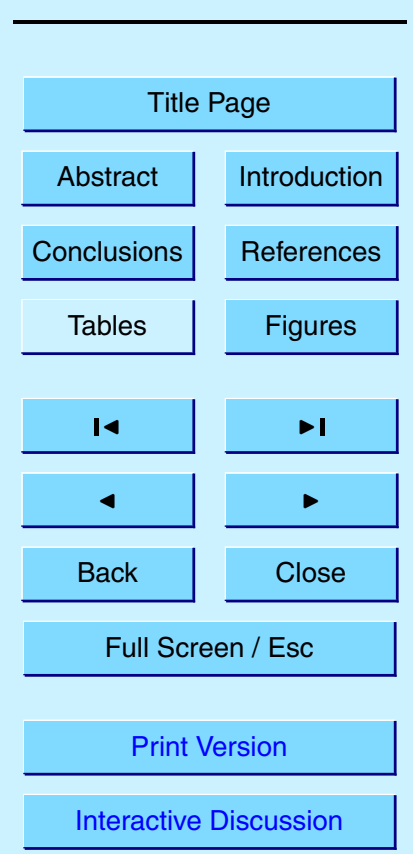

EGU 


\section{Conclusions}

The fast coagulation of primary nanoparticles as measured in our first set of experi5 ments makes it improbable that these particles survive a vehicle exhaust train. Nevertheless, in a second experimental series and using a focussed laser beam for ionisation, we found ion signals behind a scooter, a motorbike and a DI gasoline research engine that are clearly related to engine conditions. In the DI case a close correlation to the smoke number was found. We associate our signals with coagulated nanoparticles (50 ku, 4 to $5 \mathrm{~nm}$ ) and these, obviously, can be released from current vehicles in significant quantities.

\section{References}

Basile, G., Rolando, A., D'Alessio, A., D'Anna, A., and Minutolo, P.: Coagulation and carbonization processes in slightly sooting premixed flames, Proc. Combust. Inst., 29, 2391-2397, 2002.

Borghese, A. and Merola, S. S.: Detection of extremely fine carbonaceous particles in the exhausts of Diesel and spark-ignited internal combustion engines, by means of broad-band extinction and scattering spectroscopy in the ultraviolet band 190-400 nm, Proc. Combust. Inst., 27, 2101-2109, 1998.

Cecere, D., Sgro, L. A., Basile, G., D'Alessio, A., D’Anna, A., and Minutolo, P.: Evidence and characterization of nanoparticles produced in nonsooting premixed flames, Combust. Sci. Technol., 174, 377-398, 2002.

D’Alessio, A., Barone, A. C., Cau, R., D’Anna, A., and Minutolo, P.: Surface deposition and coagulation efficiency of combustion generated nanoparticles in the size range from $1 \mathrm{~nm}$ to

D'Alessio, A., D'Anna, A., Gambi, G., and Minutolo, P.: The spectroscopic characterisation of UV absorbing nanoparticles in fuel rich soot forming flames, J. Aerosol Sci., 29, 397-409, 1998.

D’Alessio, A., D’Anna, A., D’Orsi, A., Minutolo, P., Barbella, R., and Ciajolo, A.: Precursor

ACPD

5, 3847-3872, 2005

Coagulation of nanoparticles

H.-H. Grotheer et al.

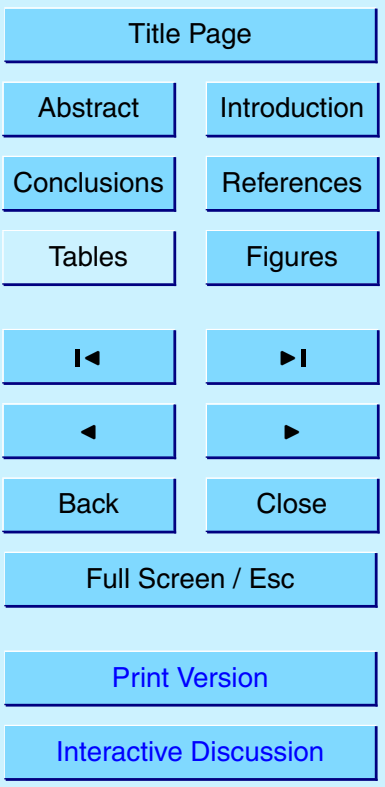

EGU 

980, 1992.

Dobbins, R. A.: The early soot particle formation in hydrocarbon flames, in: Physical and Chemical Aspects of Combustion, edited by: Dryer, F. L. and Sawyer, R. F., 107-133, 1998.

Dobbins, R. A., Fletcher, R. A., and Lu, W.: Laser microprobe analysis of soot precursor particles and carbonaceous soot, Combust. Flame, 100, 301-309, 1995.

Gonzalez Baquet, T., Barth, K. L., Grotheer, H.-H., and Aigner, M.: Detection of Combustion 5 generated Nanoparticles (NOC) behind Vehicle Engines using Mass Spectrometry, Proc. European Combustion Meeting, Louvain, April 2005.

Grotheer, H.-H., Pokorny, H., Barth, K. L., and Aigner, M.: Mass spectrometry up to 1 million mass units for the simultaneous detection of primary soot and of soot precursors (nanoparticles) in flames, Chemosphere, 57, 1335-1342, 2004.

10 Hinds, W. C.: Aerosol Technology, 2nd ed., New York 1999.

Homann, K.-H. and Wagner, H.G.: Some new aspects of the mechanism of carbon formation in premixed flames, Proc. Combust. Instit., 11, 371-379, 1967.

Maricq, M. M.: Size and charge of soot particles in rich premixed ethylene flames, Combust. Flame, 137, 340-350, 2004.

15 Maricq, M. M., Harris, S. J., and Szente, J. J.: Soot size distribution in rich premixed ethylene flames, Combust. Flame, 132, 328-342, 2003.

Merola, S. S., Gambi, G., Allouis, C., Beretta, F., Borghese, A., and D’Alessio, A.: Analysis of exhausts emitted by i.c. engines and stationary burners, by means of u.v. extinction and fluorescence spectroscopy, Chemosphere, 42, 827-834, 2001.

20 Minutolo, P., Gambi, G., D'Alessio, A., and Carlucci, S.: Spectroscopic characterisation of carbonaceous nanoparticles in premixed flames, Atmos. Environ., 33, 2725-2732, 1999.

Pokorny, H., Thierley, M., Grotheer, H. H., and Aigner, M.: The fast coagulation of combustion generated nanoparticles (NOC), Proc. European Combustion Meeting, Louvain, April 2005.

Schulz, J.: Bestimmung struktureller Eigenschaften von Ruteilchen aus Ethen/SauerstoffNiederdruckflammen, Dissertation Thesis, Universität Göttingen, 1987.

Sgro, L. A., Basile, G., Barone, A. C., D'Anna, A., Minutolo, P., Borghese, A., and D'Alessio, A.: Detection of combustion formed nanoparticles, Chemosphere, 51, 1079-1090, 2003.

Sgro, L. A., Minutolo, P., Basile, G., and D'Alessio, A.: UV-visible spectroscopy of organic carbon particulate sampled from ethylene/air flames, Chemosphere, 42, 671-680, 2001.

30 Smyth, K. C. and Mallard, W. G.: Laser-induced ionization and mobility measurements of very

Coagulation of nanoparticles

H.-H. Grotheer et al.

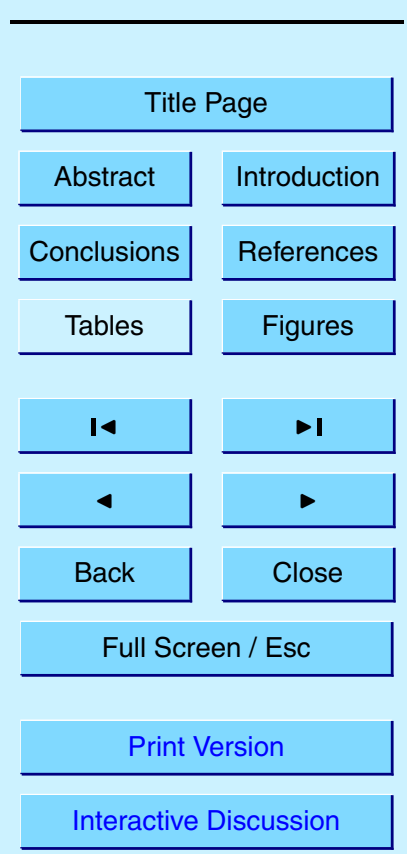

EGU 
small particles in premixed flames at the sooting limit, Combust. Sci. Technol., 26, 35-41, 1981.

Vaglieco, B. M., Merola, S. S., D'Anna, A., and D'Alessio, A.: Spectroscopic analysis and modeling of particle formation in a Diesel engine, J. Quant. Spectrosc. Radiat. Transfer, 73, 443-450, 2002.

Vander Wal, R. L.: Soot precursor carbonization: Visualization using LIF and LII and comparison using bright and dark field TEM, Combust. Flame, 112, 607-616, 1998.

5 Violi, A., D'Anna, A., D'Alessio, A., Astarita, M., and Vaglieco, B. M.: Experimental and modeling study of particle formation in high-pressure Diesel-like conditions, Proc. Combust. Inst., 28, 1241-1247, 2000.

Wersborg, B. L., Howard, J. B., and Williams, G. C.: Physical mechanisms in carbon formation in flames, Proc. Combust. Instit., 14, 929-940, 1973.

Zhao, B., Yang, Z., Li, Z., Johnston, M. V., and Wang, H.: Particle size distribution function of incipient soot in laminar premixed ethylene flames: Effect of flame temperature, Proc. Combust. Instit. 30, 1441-1448, 2005.

390 Zhao, B., Yang, Z., Wang, J., Johnston, M. V., Wang, H., Wexler, A. S., Balthasar, M., and Kraft, M.: Measurement and numerical simulation of soot particle size distribution functions in a laminar premixed ethylene-oxygen-argon flame, Combust. Flame, 133, 173-188, 2003.

Zhao, B., Yang, Z., Wang, J., Johnston, M. V., and Wang, H.: Analysis of soot nanoparticles in a laminar premixed ethylene flame by scanning mobility particle sizer, Aerosol Sci. Technol., 37, 611-620, 2003.

\section{ACPD}

5, 3847-3872, 2005

Coagulation of nanoparticles

H.-H. Grotheer et al.

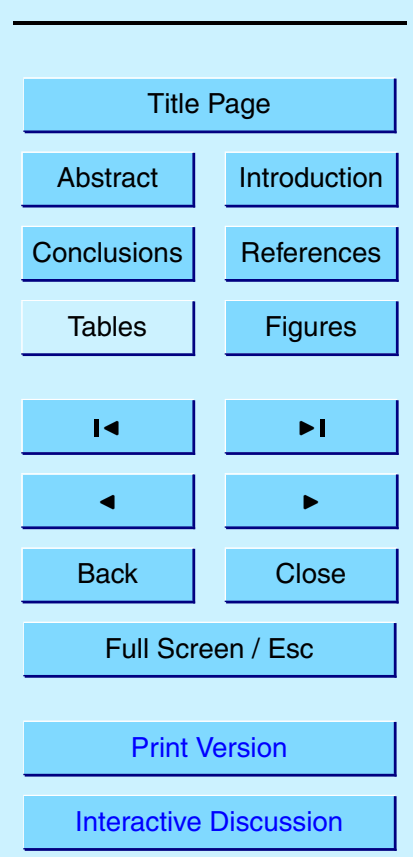




\section{ACPD}

$5,3847-3872,2005$

premixed flame; ca. 100 mbar ethylene, acetylene/oxygen

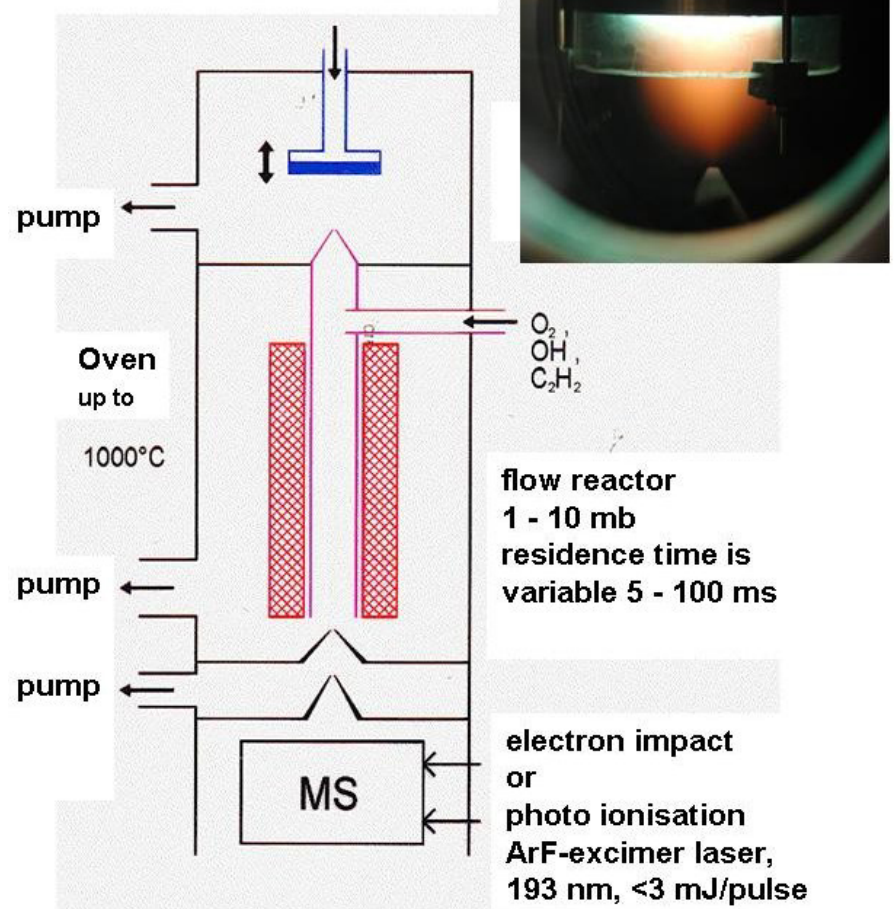

Coagulation of nanoparticles

H.-H. Grotheer et al.

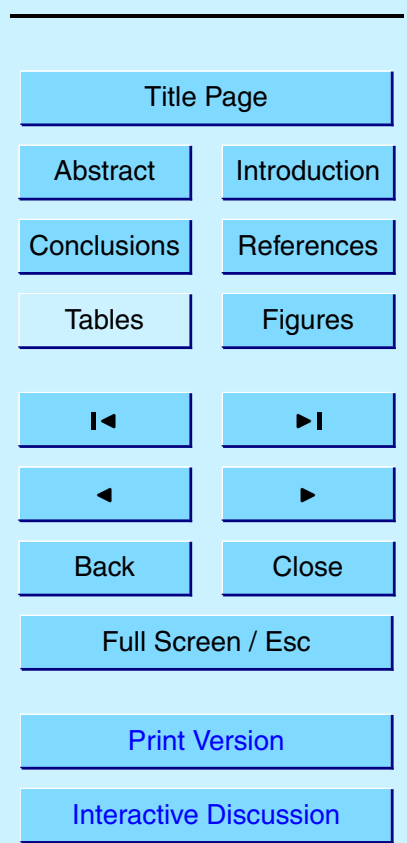

Fig. 1. Hybrid setup of low pressure burner, flow reactor and mass spectrometer. 


\section{ACPD}

5, 3847-3872, 2005

Coagulation of nanoparticles

H.-H. Grotheer et al.
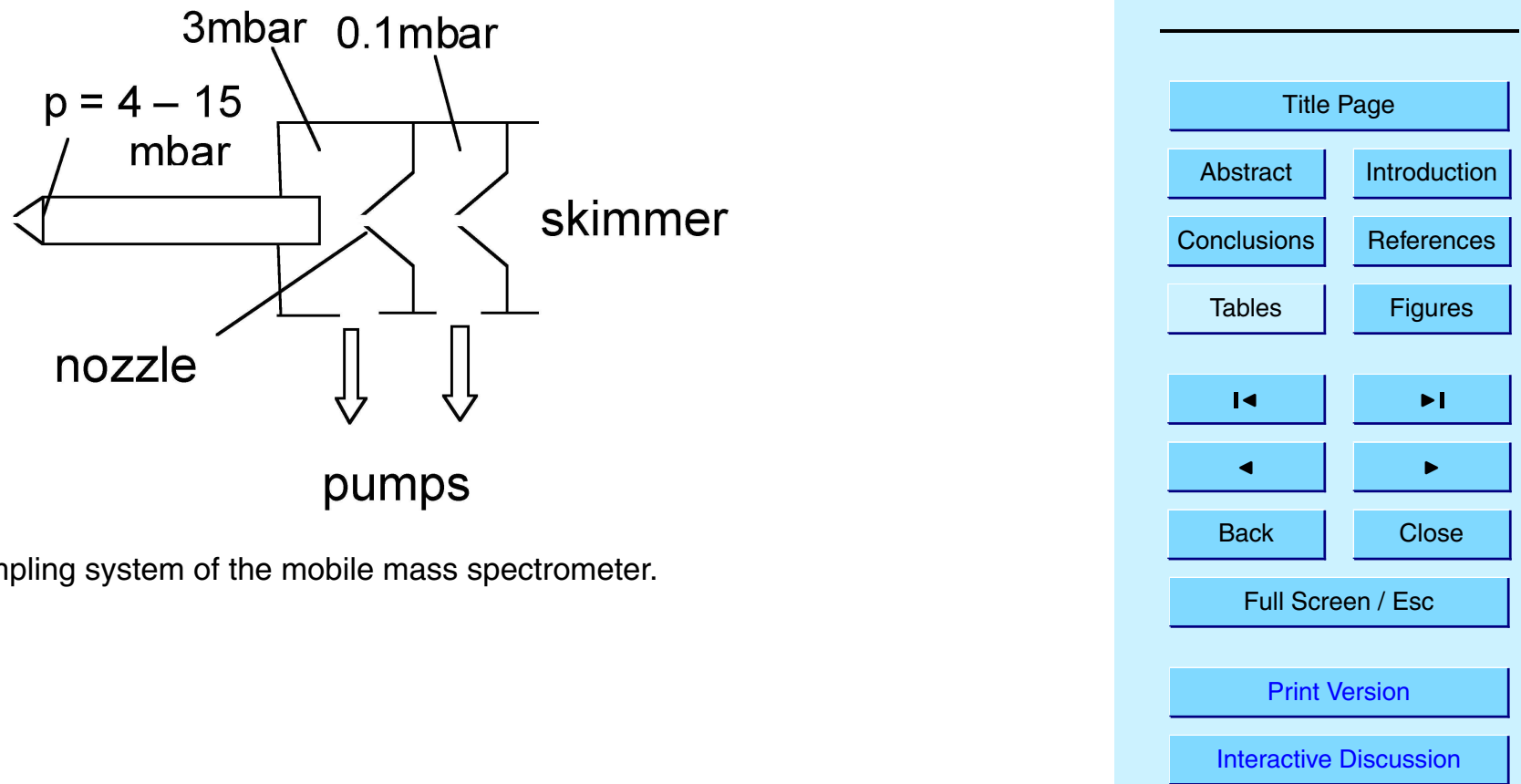

Fig. 2. Fast flow sampling system of the mobile mass spectrometer. 


\section{ACPD}

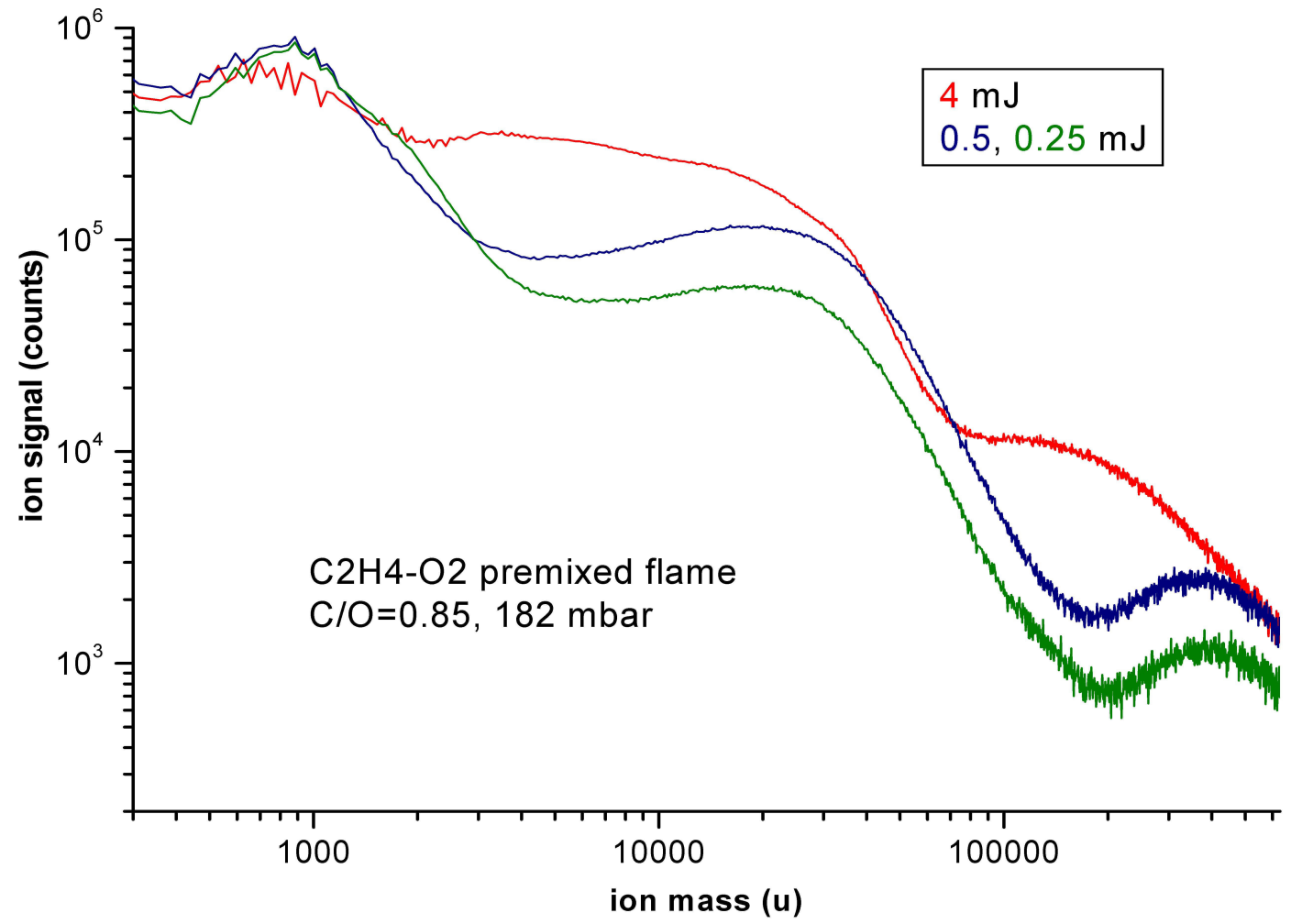

5, 3847-3872, 2005

Coagulation of nanoparticles

H.-H. Grotheer et al.

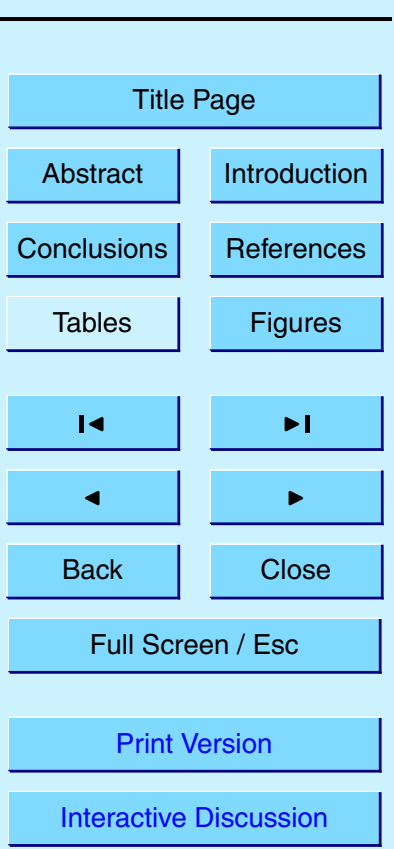

Fig. 3. Particle spectra from a premixed low pressure flame for different pulse energies of the ionisation laser. Note: loglog display. 


\section{ACPD}

5, 3847-3872, 2005

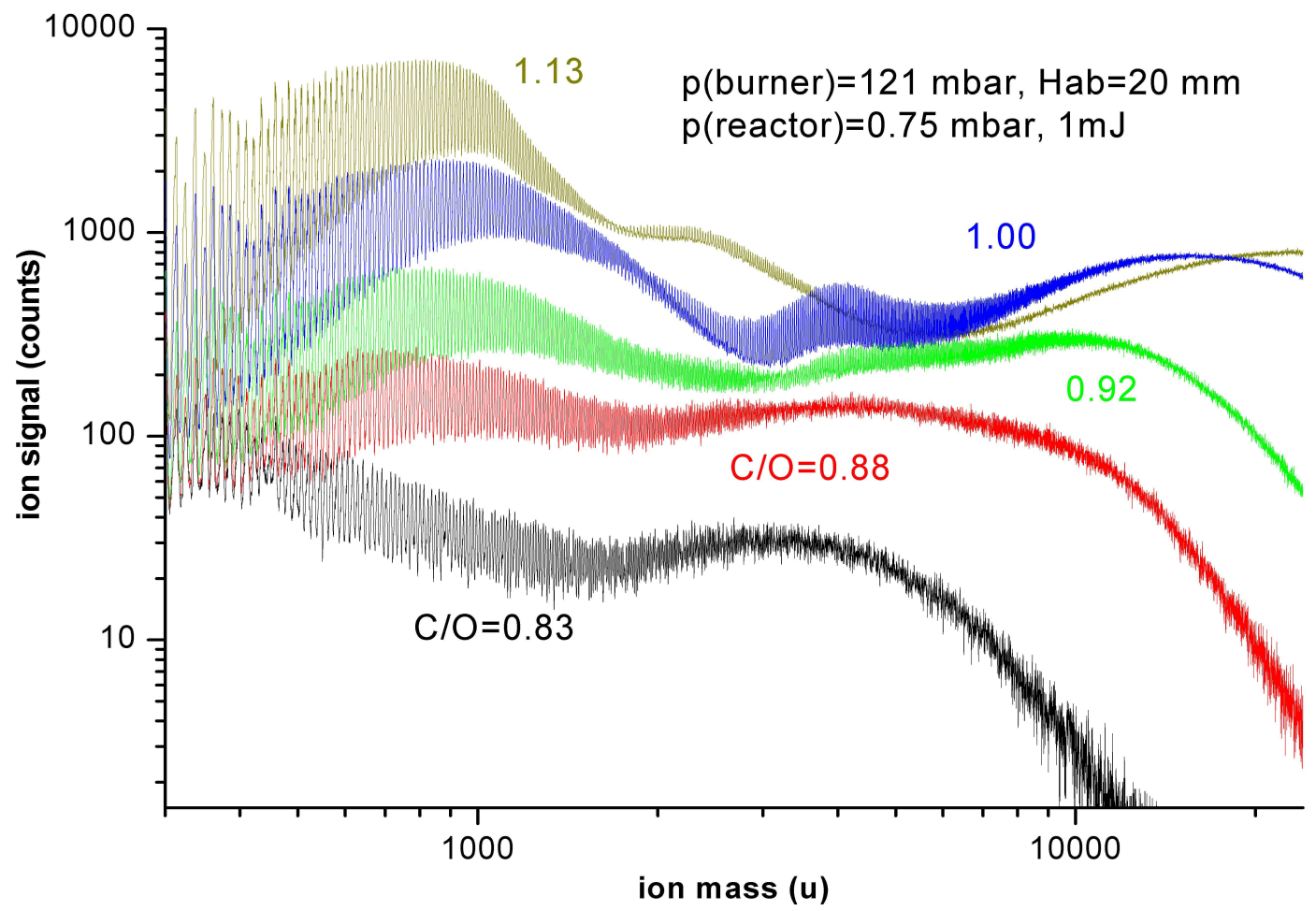

\section{Coagulation of} nanoparticles

H.-H. Grotheer et al.

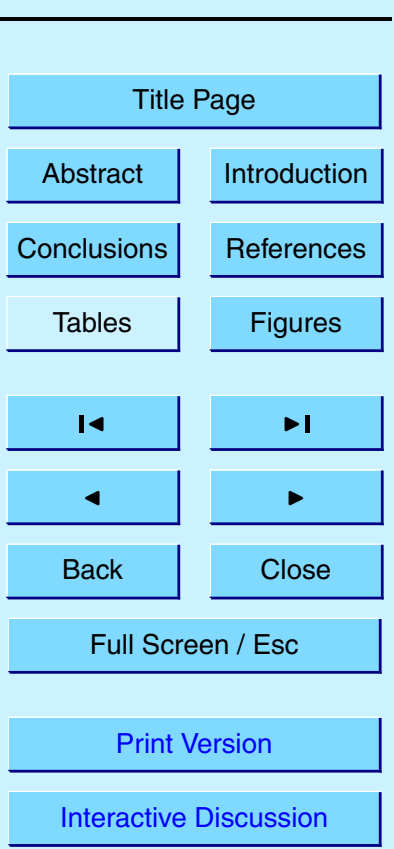

Fig. 4. Nanoparticle mass spectra as a function of stoichiometry. 


\section{ACPD}

$5,3847-3872,2005$

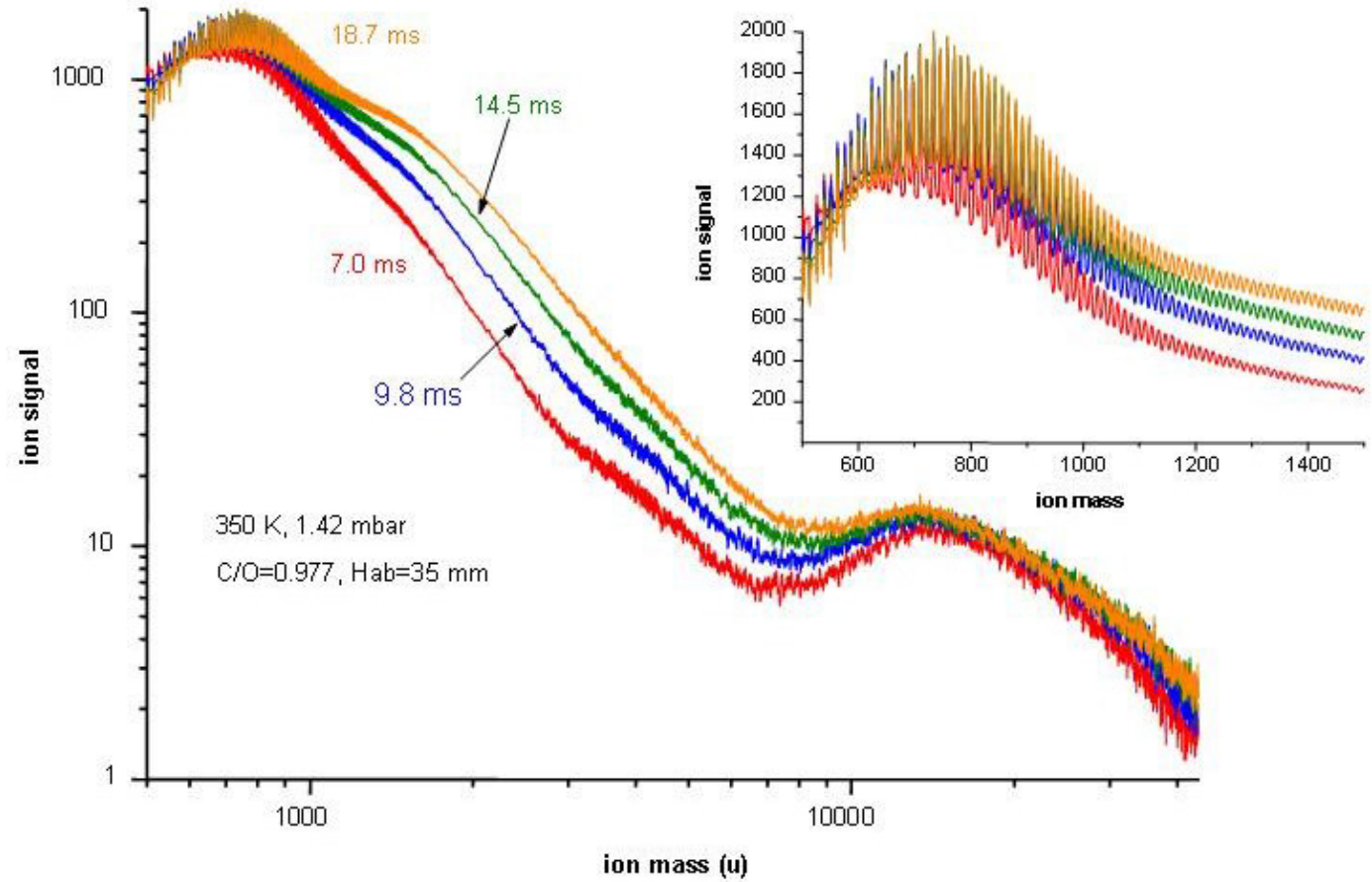

\section{Coagulation of nanoparticles}

H.-H. Grotheer et al.

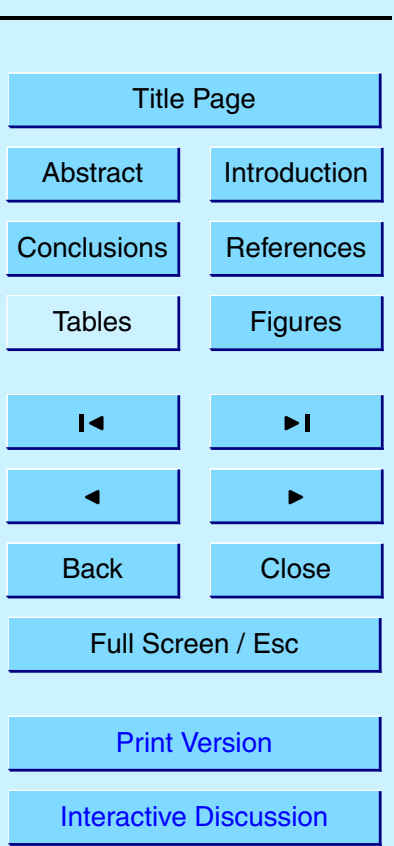

Fig. 5. Nanoparticle mass spectra for different reactor residence times at low temperature.

EGU 


\section{ACPD}

$5,3847-3872,2005$

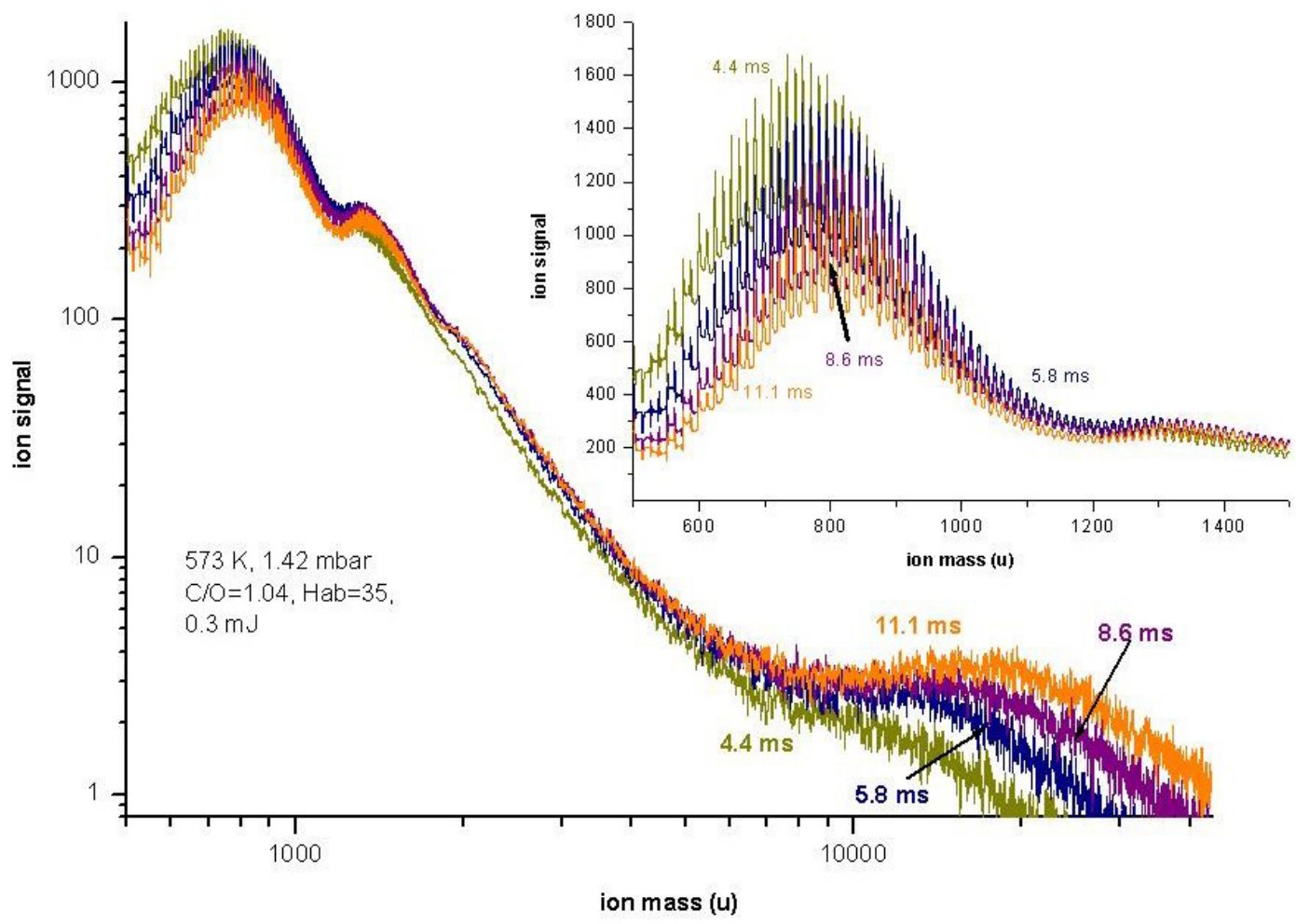

\section{Coagulation of nanoparticles}

H.-H. Grotheer et al.

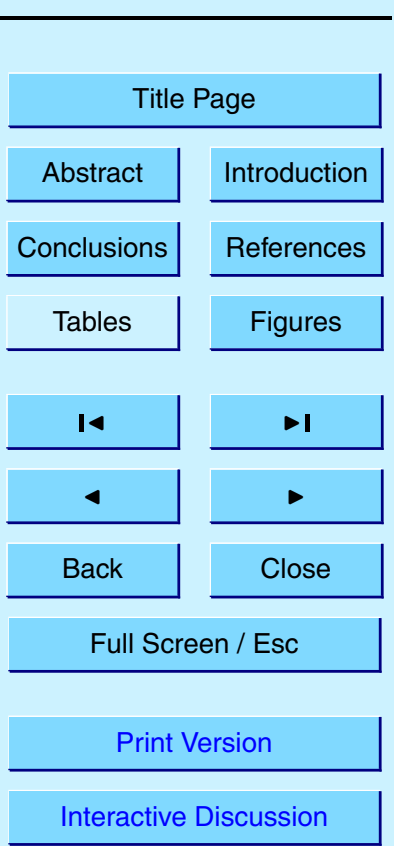

Fig. 6. Nanoparticle mass spectra for different reactor residence times at elevated temperature.

EGU 


\section{ACPD}

5, 3847-3872, 2005

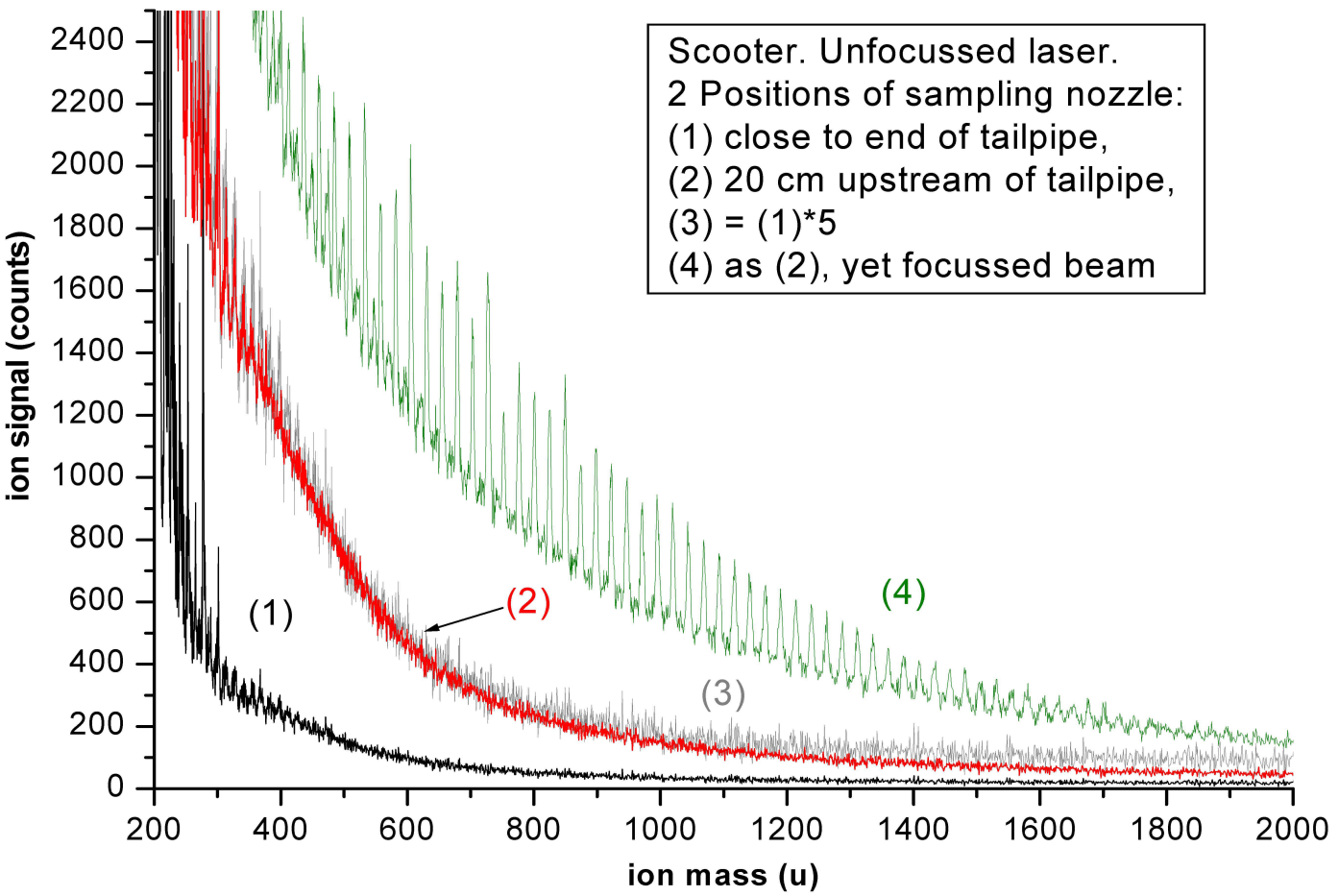

\section{Coagulation of nanoparticles}

H.-H. Grotheer et al.

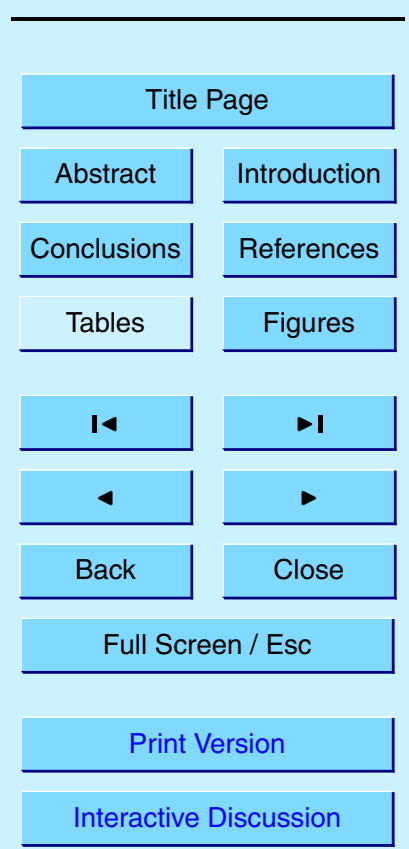

Fig. 7. Nanoparticle spectra from the two-stroke scooter for different sampling positions and for Interactive Discussion

EGU 


\section{ACPD}

5, 3847-3872, 2005

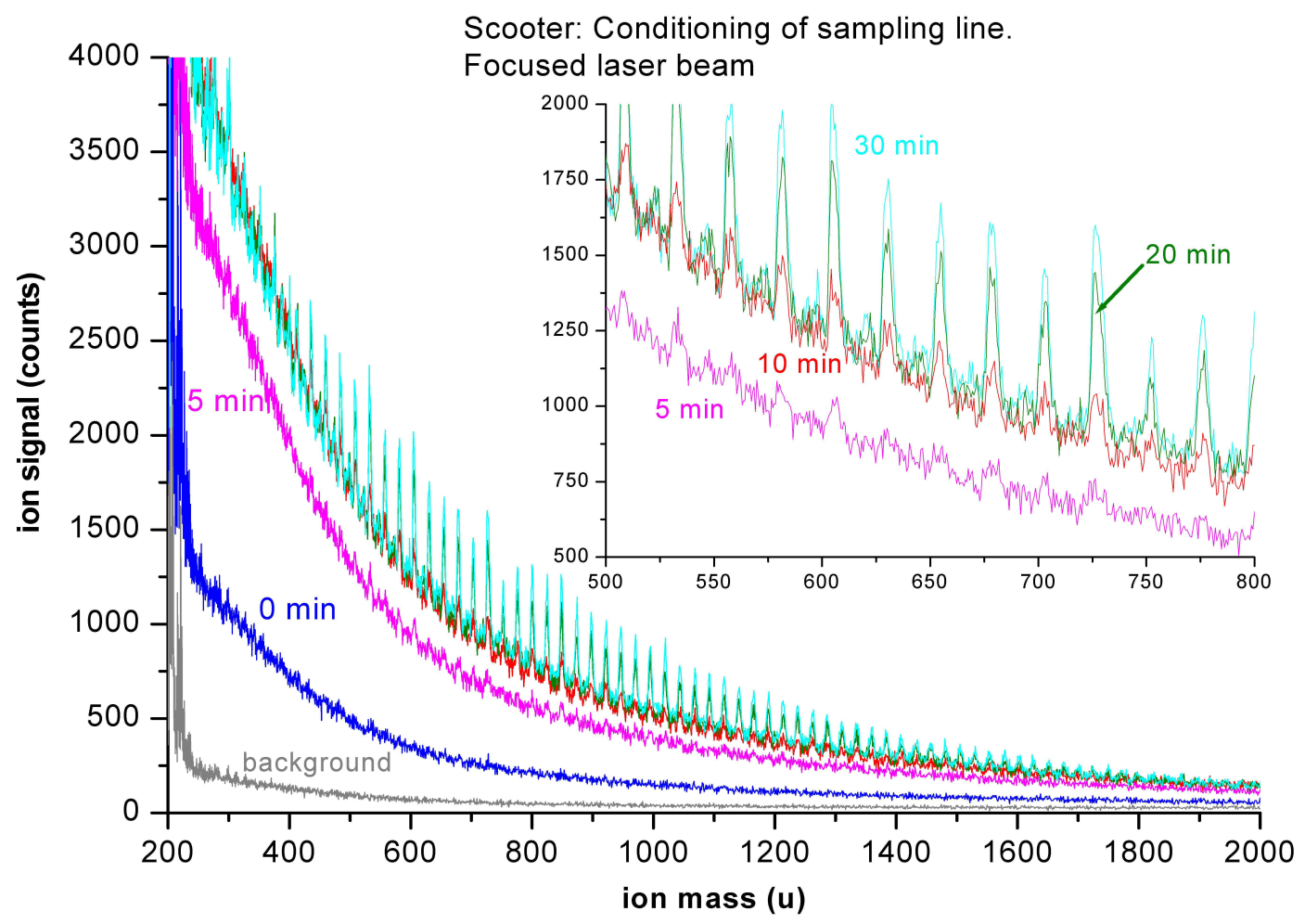

\section{Coagulation of nanoparticles}

H.-H. Grotheer et al.

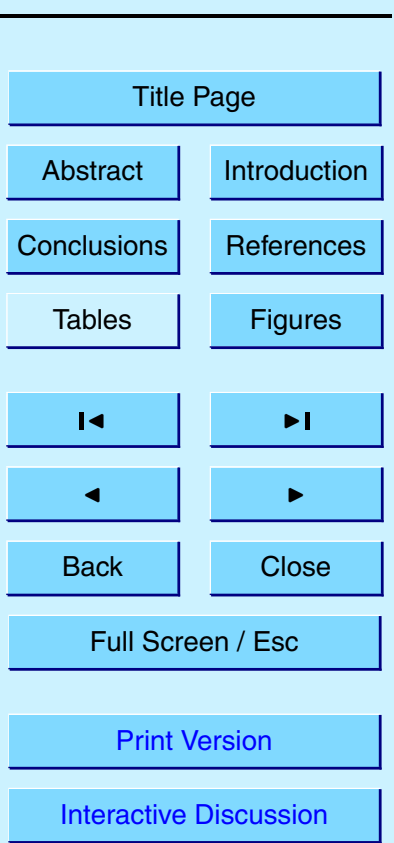

Fig. 8. Development of nanoparticle spectra during the ageing pocess of the sampling line.

EGU 


\section{ACPD}

$5,3847-3872,2005$

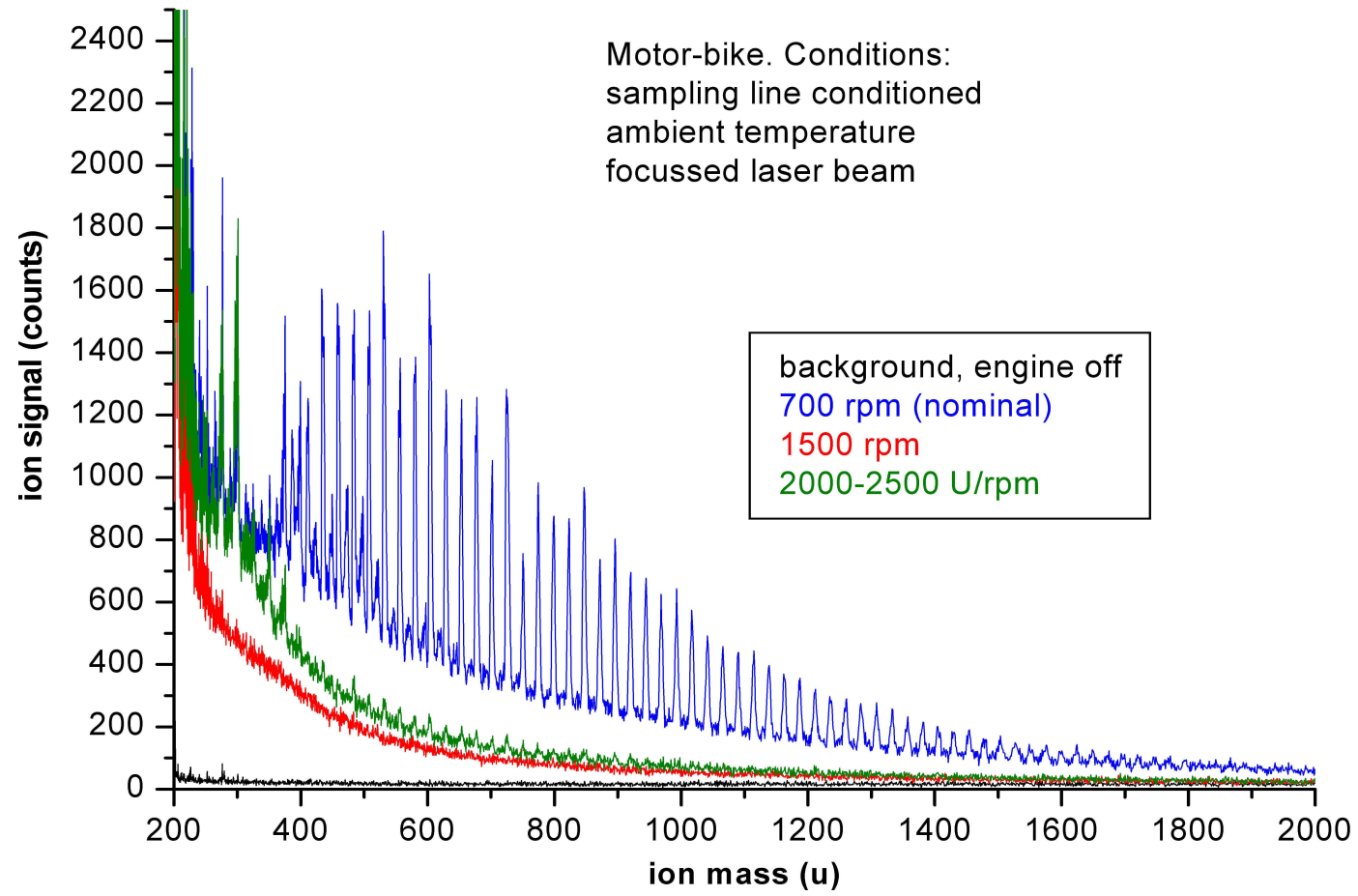

\section{Coagulation of nanoparticles}

H.-H. Grotheer et al.

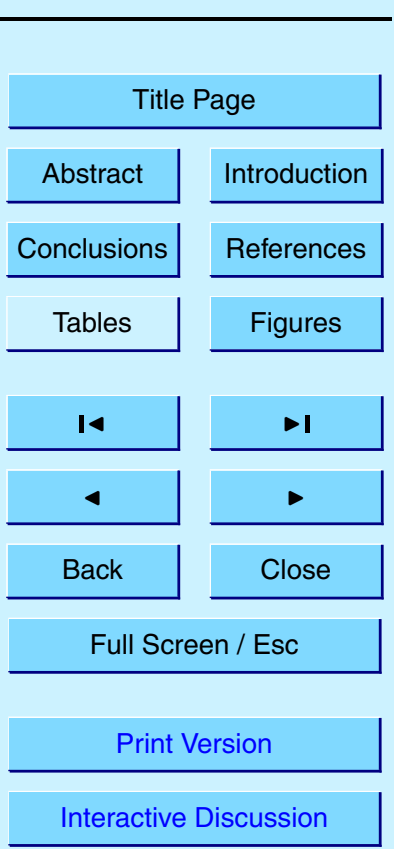

Fig. 9. Nanoparticle spectra from the four-stroke bike in dependence of the engine speed. 


\section{ACPD}

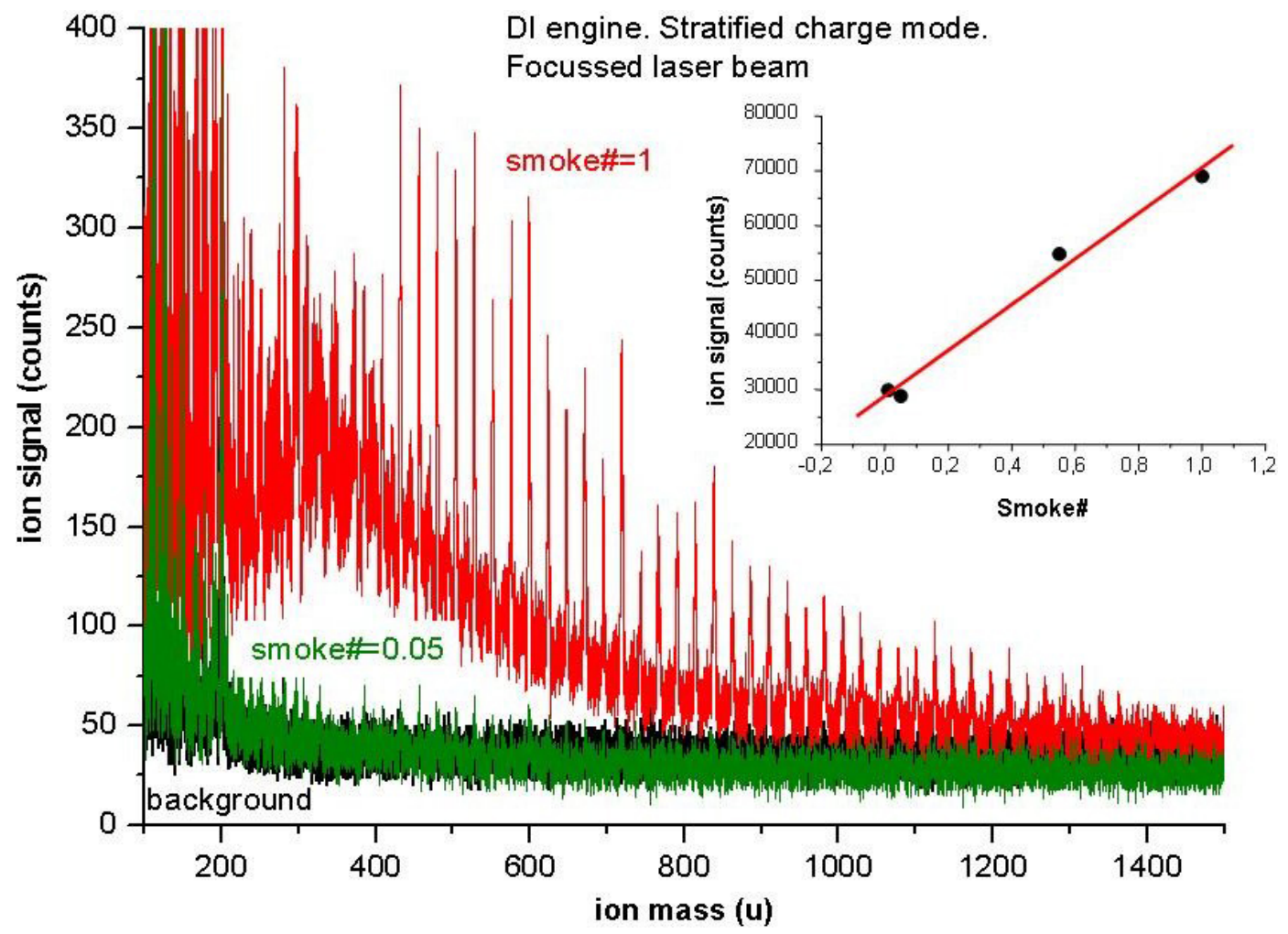

5, 3847-3872, 2005

Coagulation of nanoparticles

H.-H. Grotheer et al.

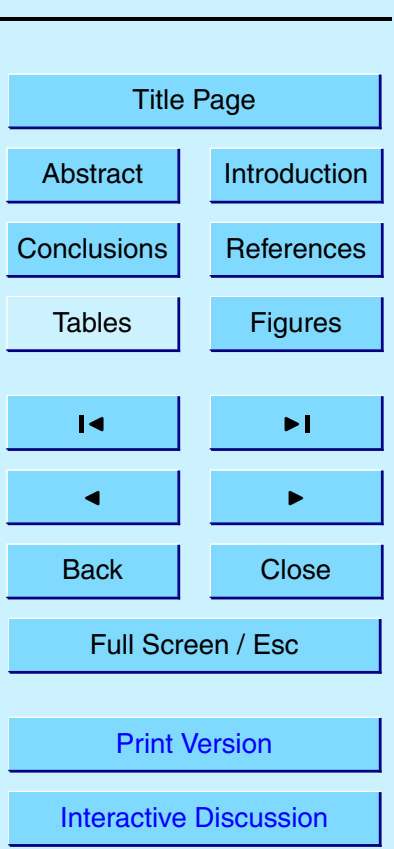

1000 u) vs. smoke number.

EGU 